\title{
Penentuan Komposisi Bahan Bakar Nabati Dalam Bahan Bakar Minyak Campuran Menggunakan Metode Direct Counting C-14
}

\section{Determination of Biofuel Composition In Mixed Oil Fuel Using Direct Counting C-14 Method}

\author{
Neneng Laksminingpuri ${ }^{1 *}$, Moch Faizal Ramadhani ${ }^{1}$, Nurfadhlini ${ }^{1}$, Lies Aisyah ${ }^{2}$ \\ ${ }^{1}$ Pusat Aplikasi Isotop dan Radiasi-BATAN \\ Jl. Lebak Bulus Raya 48, Ps. Jumat, Jakarta 12440, Indonesia \\ ${ }^{2}$ Puslitbangtek Migas, Kementrian ESDM \\ J1. Ciledug Raya, Kavling 109, Jakarta 12230, Indonesia \\ *E-mail: laksmini@batan.go.id
}

Naskah diterima: 17 Juni 2021, direvisi: 15 November 2021, disetujui: 27 November 2021

DOI: 10.17146/eksplorium.2021.42.2.6363

\begin{abstract}
ABSTRAK
Telah dilakukan penentuan komposisi bahan bakar nabati (BBN) dalam bahan bakar minyak campuran (BBMC) dengan metode direct counting C-14. Penentuan komposisi BBN dalam BBMC dilakukan dengan cara memipet $10 \mathrm{~mL}$ BBMC ke dalam vial gelas kemudian ditambahkan $10 \mathrm{~mL}$ larutan sintilator Ultima Gold F (UGF) ke dalamnya. Vial tersebut dikocok agar campuran menjadi homogen kemudian dicacah menggunakan LSC (Liquid Scintillation Counter) Elmer Perkin 2900TR selama 20 menit sebanyak 30 siklus. Hasil pencacahan ditampilkan dalam bentuk tSIE (transformed external standard spectrum) dan cpm (cacahan permenit). Hasil analisis memperlihatkan nilai cpm yang meningkat seiring kenaikan persentase BBN dalam BBMC. Nilai cpm terendah dan tertinggi untuk sampel bensin, avtur, dan solar berturut-turut adalah 14,2363 dan 62,0343, 10,664 dan 44,535, serta 9,410 dan 61,789. Terdapat korelasi kuat antara nilai tSIE dan nilai cpm pada bensin dan solar tapi tidak pada avtur. Hasil analisis terhadap sampel uji menunjukkan bahwa sampel tersebut berada di luar grafik deret sampel. Metode direct counting ini diharapkan dapat menjadi referensi dalam uji mutu BBMC.
\end{abstract}

Kata kunci: tSIE, cpm, BBN, BBMC, LSC, direct counting, C-14

\begin{abstract}
The composition of biofuel (BF) in mixed oil fuel $(M O F)$ has been determined using the $C$-14 direct counting method. Determination of the composition of BF in MOF was carried out by pipetting $10 \mathrm{~mL}$ of BBMC into a glass vial and then adding $10 \mathrm{~mL}$ of Ultima Gold $F(U G F)$ scintillator solution into it. The vial was shaken so that the mixture became homogeneous and then counted using the Elmer Perkin 2900TR LSC (Liquid Scintillation Counter) for 20 minutes for 30 cycles. The results of the counting are displayed in the form of tSIE (transformed external standard spectrum) and cpm (counts per minute). The results of the analysis show that the value of cpm increases with the increase in the percentage of BF in MOF. The lowest and highest cpm values for gasoline, avtur, and diesel samples were 14.2363 and 62.0343, 10.664 and 44.535, and 9.410 and 61.789, respectively. There is a strong correlation between tSIE and cpm values for gasoline and diesel but not for avtur. The results of the analysis of the test sample indicate that the sample is outside the sample series graph. This direct counting method is expected to be a reference in the BBMC quality test.
\end{abstract}

Keywords: $t S I E$, cpm, BF, MOF, LSC, direct counting, $C-14$ 


\section{PENDAHULUAN}

Sektor energi masih memiliki peran yang vital dan menjadi salah satu faktor strategis perekonomian Indonesia. Selain berfungsi sebagai pemasok kebutuhan, bahan baku industri, pembuka lapangan kerja, aset investasi, dan stimulus pertumbuhan di daerah, sektor energi juga merupakan penopang utama penerimaan negara dalam APBN. Pendapatan negara pada tahun 2014 mencapai Rp. 464,25 triliun dari bidang energi dan sumber daya mineral. Penerimaan tertinggi berasal dari minyak dan gas bumi sebesar Rp320,25 triliun, diikuti batubara sebesar Rp142 triliun, dan sisanya dari sektor lain [1]. Pertumbuhan konsumsi energi Indonesia pada tahun 2014 meningkat sebanyak 3,1\%. Dari jumlah total energi yang dikonsumsi itu, porsi terbesar masih dipegang oleh energi fosil yang terdiri dari minyak $42,3 \%$, batubara $34,8 \%$, dan gas $19,8 \%$. Sementara energi baru dan terbarukan (EBT) yang memiliki potensi besar untuk masa depan hanya memiliki porsi 1,3\% [2]. Permasalahan yang timbul akibat penggunaan energi fosil adalah sumber dayanya yang makin sedikit, permintaannya yang makin naik (sehingga menyebabkan kenaikan harga), dan pemanasan global akibat pembakarannya [3].

Bahan bakar fosil seperti minyak, batubara, dan gas merupakan sumber energi yang terbatas ketersediaannya. Sumber daya tersebut hanya dapat memenuhi kebutuhan energi selama beberapa dekade ke depan. Peningkatan penggunaan bahan bakar fosil di Indonesia, Asia, serta negara-negara barat akan mempercepat habisnya sumber energi tersebut. Oleh karena itu, pencarian sumber energi alternatif terus dilakukan selama beberapa tahun terakhir.

Tantangan lain yang mesti dihadapi adalah upaya pengurangan emisi karbon dioksida $\left(\mathrm{CO}_{2}\right)$ untuk menghindari peningkatan suhu global. $\mathrm{CO}_{2}$ telah diterima secara umum sebagai salah satu penyebab pemanasan global meskipun masih diperlukan informasi lebih lanjut untuk dapat sepenuhnya memahami keterlibatan $\mathrm{CO}_{2}$ dalam peningkatan suhu global. Upaya pencegahan peningkatan suhu global ini disepakati banyak negara dalam Protokol Kyoto dan ditindaklanjuti dengan pengurangan emisi $\mathrm{CO}_{2}$ di masing-masing negara selama beberapa tahun mendatang.

Salah satu solusi untuk memperlambat habisnya sumber energi fosil dan mengurangi emisi $\mathrm{CO}_{2}$ adalah penggunaan energi terbarukan (salah satunya berupa energi nabati) [1]. Produksi bahan bakar nabati (BBN) yang bersumber dari tebu, jagung, dan bahan alam lainnya telah banyak diteliti dan digunakan sebagai campuran bahan bakar fosil (BBF).

Minyak yang diperoleh dari tumbuhan disebut minyak nabati. Minyak tersebut dapat menjadi bahan baku bagi pembuatan biosolar. Beberapa contoh minyak nabati antara lain minyak sawit, minyak inti sawit, minyak kelapa, minyak kacang tanah, minyak jarak pagar, minyak nyamplung, minyak kelor, minyak kesambi, minyak kapok/randu, lemak rambutan, dan lain-lain [4].

BBN dapat menjadi salah satu opsi sumber energi yang aman dan berkelanjutan di sektor transportasi. BBN beroperasi di mesin seperti solar sehingga diperlukan penentuan elemen-elemen yang terkandung di dalam BBN.

Pengembangan energi terbarukan telah mendapat dukungan dari pemerintah berupa Perpres nomor 5 tahun 2006, yang isinya adalah bahwa 5\% kebutuhan energi nasional dipenuhi dari sumber energi nabati sehingga pada tahun 2025 diharapkan porsinya dapat mencapai 20\%. Berdasarkan Permen ESDM 
nomor 25 tahun 2013, dilakukan peningkatan konsentrasi biosolar (termasuk dalam BBMC) dari 5\% menjadi 10\% per September 2013. Kendala yang muncul berkaitan dengan kebijakan pemerintah tersebut adalah bagaimana cara melakukan uji mutu untuk mengontrol kualitas produk BBMC secara optimal tapi dengan biaya yang relatif murah. Oleh karena itu, perlu ditentukan sebuah cara/metode yang efektif dan efisien untuk menjaga kualitas produk BBMC sehingga aman digunakan [5]. Aplikasi metode Liquid Scintillation Counting (LSC) dalam penentuan konsentrasi BBN pada BBMC mengalami perkembangan di negara-negara Uni Eropa. Metode LSC ini lebih detail merupakan metode penentuan konten $\mathrm{C}$-14 secara kuantitatif yang dapat diaplikasikan untuk memenuhi tujuan yang dimaksud [6].

Jumlah C-14 dalam BBF dan BBN sangat berbeda. Jumlah C-14 dalam BBF sangat kecil sampai tidak ada sementara jumlah C-14 dalam minyak nabati mendekati jumlah maksimum, yaitu 15,3 DPM/g C [7]-[10]. Oleh karena itu, penambahan BBN ke dalam BBF akan meningkatkan jumlah C-14 yang dapat dilacak dalam uji mutu sehingga perbandingan $\mathrm{BBN}$ dan $\mathrm{BBF}$ dapat diketahui.

Karakterisasi BBN dengan spektrometer sintilasi cair didasarkan pada penentuan aktivitas C-14 dalam sampel. C-14 adalah radionuklida kosmogenik yang diproduksi di atmosfer dari N-14 oleh neutron. Produksi C14 di udara relatif konstan. Pada saat yang sama C-14 mengalami peluruhan radioaktif menjadi N-14 dengan waktu paruh kira-kira 5700 tahun. Proses ini berlangsung di atmosfer dalam kesetimbangan. Organisme (khususnya tumbuhan) menyerap C-14 melalui mekanisme fotosintesis, konsumsi, atau inhalasi. Oleh karena itu, dalam jaringan hidup selalu terdapat isotop C-14 yang terus bersirkulasi. Setelah tumbuhan mati, penyerapan karbon terhenti sehingga proporsi isotop C-14 berkurang sampai habis. C-14 dalam BBF terus meluruh dan berkurang tetapi aktivitasnya masih dapat terdeteksi. Dengan demikian, komposisi BBN dan BBF dalam BBMC dapat diketahui dengan mengukur aktivitas C-14 pada sampel. Spektrometer sintilasi cair cocok digunakan untuk menentukan konten C-14 dalam sampel cairan.

\section{TEORI}

Metode paling sederhana untuk pengukuran LSC secara langsung adalah mencampur sampel dengan larutan koktail yang sesuai. Hal ini hanya dapat diterapkan pada bahan bakar cair [11], [12]. Metode ini tidak memerlukan preparasi sampel dan efisiensi pengukuran bergantung pada warna sampel [13].

\section{Cara Menghitung Fraksi Biogenik}

Hasil pengukuran aktivitas $\mathrm{C}-14$ disajikan sebagai aktivitas spesifik $\mathrm{C}-14$ relatif $\left(\mathrm{a}^{14} \mathrm{C}\right)$ yang dinyatakan dalam persentase karbon modern (pMC), 100 pMC setara dengan aktivitas spesifik $226 \mathrm{~Bq} / \mathrm{kg}$ C [14]. Suatu bahan bakar dapat terdiri dari fraksi komponen biogenik $\mathrm{f}_{\text {bio }}$ dan aktivitas ${ }^{14} \mathrm{C}_{\text {bio }}, \mathrm{a}^{14} \mathrm{C}_{\text {bio }}$ serta fraksi komponen fosil $\mathrm{f}_{\mathrm{f}}$ dan aktivitas ${ }^{14} \mathrm{C}_{\mathrm{f}}$, $a^{14} C_{f}$. Diperoleh bahwa $f_{f}+f_{\text {bio }}=1$. Aktivitas C14 yang terukur dari bahan campuran tersebut, $\mathrm{a}^{14} \mathrm{C}$, dapat ditentukan dengan formula berikut.

$$
a{ }^{14} C=f_{f} \cdot a{ }^{14} C_{f}+f_{b i o} \cdot a{ }^{14} C_{b i o}
$$

Dalam BBF, semua C-14 telah meluruh dan $\mathrm{a}^{14} \mathrm{C}_{\mathrm{f}}=0$ pMC sehingga fraksi komponen biogenik dapat didefinisikan sebagai berikut.

$$
f_{\text {bio }}=a^{14} \mathrm{C} / a^{14} C_{\text {bio }}
$$

Pengukuran kandungan C-14 menggunakan direct LSC merupakan cara yang paling sederhana dan cepat karena tidak membutuhkan preparasi sampel. Namun, minyak nabati yang umumnya diproduksi dari 
rape seed, bunga matahari, kedelai, atau minyak hewani memiliki intensitas warna kekuningan yang berbeda-beda. Perbedaan warna ini dapat menimbulkan perbedaan sifat quenching sampel sehingga memengaruhi efisiensi pengukuran [13]. Solusi yang telah dilakukan untuk mengatasi kelemahan metode ini adalah penghilangan warna [15] atau pembuatan kurva quenching untuk masingmasing BBMC yang telah diketahui komposisinya [11], [12]. Sampel yang berasal dari BBF murni digunakan sebagai sampel background.

Korelasi antara laju pencacahan berbagai sampel BBF dan nilai standard quench parameter (SQP) merupakan standar yang dihitung menggunakan standar eksternal ${ }^{152} \mathrm{Eu}$ pada LSC Quantulus. Nilai SQP merepresentasikan spektrum ${ }^{152} \mathrm{Eu}$ yang terbagi menjadi dua kelompok, yaitu yang mengandung $99 \%$ dan $1 \%$ dari cacahan totalnya. Untuk mengetahui korelasinya, bensin, akuabides, dan benzena bebas C-14 digunakan sebagai sampel background pada pengukuran C-14 (teknik LSC-benzena). Nilai laju pencacahan semua sampel background menunjukkan hasil yang linier dengan nilai SQP antara 400 (air) dan 900 (benzena), dengan $\mathrm{R}^{2}=0,94$ (Gambar 1). Kurva korelasi ini disebut dengan background calibration curve (BCC).

Berbagai macam larutan biogenik telah tersedia secara komersial dan memiliki sifat quenching yang berbeda-beda. Larutan tersebut dapat digunakan untuk membuat modern calibration curve (MCC). Material yang digunakan untuk membuat MCC merupakan material yang digunakan dalam BBMC. Dengan adanya kurva BCC dan MCC, liquid scintillation counting dapat diusulkan sebagai teknik alternatif untuk evaluasi data BBMC. Teknik yang diusulkan tersebut memanfaatkan kelemahan utama dari metode ini, yaitu color quenching. Quenching digunakan sebagai parameter kalibrasi terpisah untuk sampel modern dan sampel bebas C-14.

Prosedur evaluasi data dari sampel yang tidak diketahui komposisinya adalah sebagai berikut:

1. mengukur SQP dan laju cacahan $(C)$ dari sampel yang tidak diketahui komposisinya;

2. menentukan laju cacahan background $\left(C_{B}\right)$ sesuai dengan nilai SQP yang terukur dari BCC; dan

3. menentukan laju cacahan sampel biogenik $\left(C_{b i o}\right)$ sesuai dengan nilai SQP yang terukur dari MCC.

Fraksi komponen biogenik dalam sampel BBMC kemudian dihitung sebagai rasio laju cacahan sampel bersih terhadap sampel biogenik (dikomparasikan dengan persamaan 2).

$$
f_{\text {bio }}=\frac{C-C_{B}}{C_{b i o}-C_{B}}
$$

Semua sampel, baik BBMC maupun BBF murni, harus diukur dalam kondisi yang sama, yaitu menggunakan vial kaca low-potassium ukuran $20 \mathrm{~mL}$, scintillation cocktail UGF, dan rasio sampel:UGF 1:1. Spektrum direkam dengan perangkat LSC Quantulus yang kemudian dievaluasi pada window antara channel 124 dan 570. Pengaturan parameter pada Quantulus sama dengan pengukuran C14 lainnya, yaitu high coincidence bias dan pulse amplitude comparison (PCA) pada nilai 100. Lama pengukuran adalah 600 menit dibagi dalam 20 interval (masing-masing 30 menit) dan nilai SQP diukur pada setiap siklus.

Alat pencacah sintilasi cair di Laboratorium Hidrologi dan Panas Bumi bermerk Perkin Elmer 2900TR. Hasil pengukuran quenching-nya dinyatakan dalam tSIE (trasformed External Standard 
Spectrum). tSIE juga disebut SQP pada alat pencacah Quantulus yang berasal dari spektrum standar eksternal. Pada LSC Perkin
Elmer 2900TR aktivitas C-14 diukur pada window 0-186 dan durasi pengukuran sama dengan LSC Quantulus.

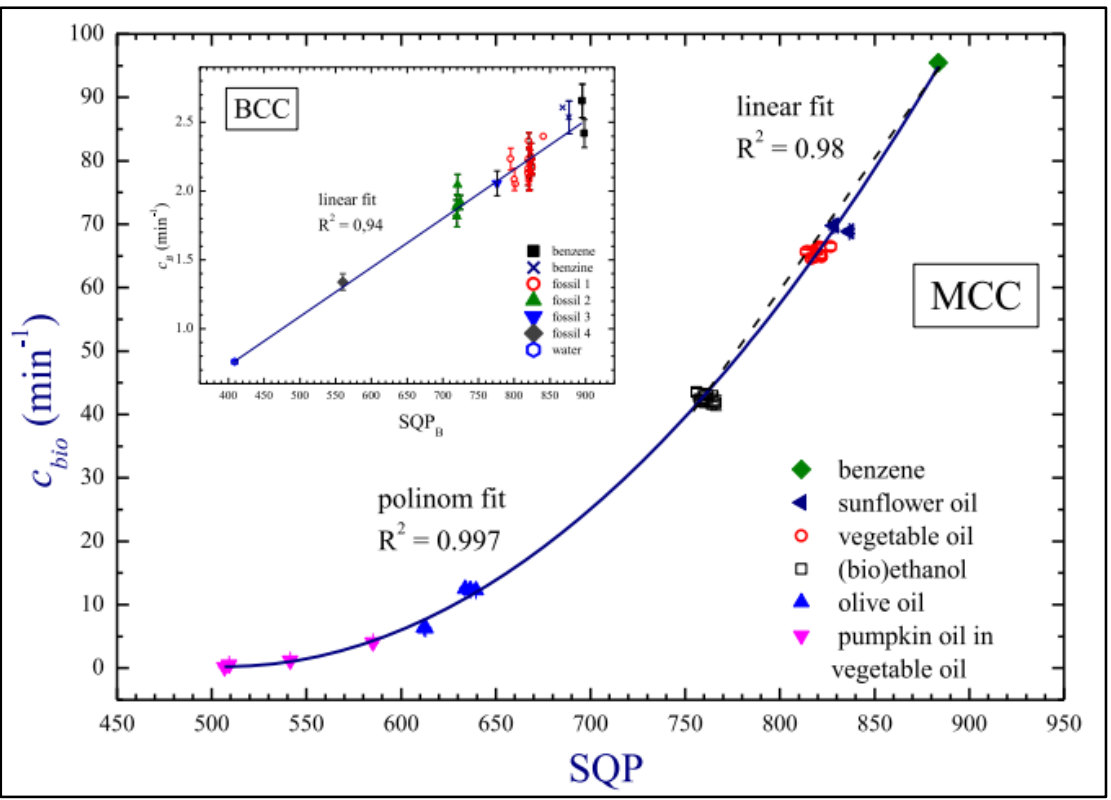

Gambar 1. Grafik background calibration curve (BCC) dan modern calibration curve (MCC) [16].

\section{METODOLOGI}

\section{Bahan dan Alat}

Bahan yang digunakan adalah sampel bensin, avtur, solar, dan larutan sintilator UGF. Alat yang digunakan adalah pipet dan alat pencacah sintilator cair merk Perkin Elmer 2900TR tipe Tricarb.

\section{Metode Direct Counting}

Sampel BBMC dengan rentang konsentrasi $0-100 \%$ dipipet $10 \mathrm{~mL}$ dan dimasukkan ke dalam vial $20 \mathrm{~mL}$ lalu ditambahkan $10 \mathrm{~mL}$ larutan sintilator UGF. Vial dikocok sampai sampel homogen lalu dicacah menggunakan perangkat LSC selama 20 menit sebanyak 30 siklus sehingga total waktu yang dibutuhkan adalah 600 menit.

\section{HASIL DAN PEMBAHASAN}

Telah dilakukan analisis C-14 terhadap tiga jenis sampel BBMC, yaitu bensin, avtur, dan solar dengan metode direct counting menggunakan perangkat LSC. Pada tahap pertama, analisis dilakukan secara menyeluruh terhadap sampel. Counting untuk setiap sampel dilakukan selama 20 menit dengan 30 siklus.

Pengambilan cuplikan sampel yang akan dianalisis dilakukan dengan tip pipette ukuran $10 \mathrm{~mL}$ dalam keadaan bersih dan kering. Untuk menghindari cross contamination pada pengambilan sampel, satu tip pipette hanya digunakan untuk satu sampel. Larutan UGF buatan Perkin Elmer digunakan sebagai sintilator dan ditambahkan ke dalam sampel yang telah disiapkan dengan perbandingan 1:1. Sintilator UGF dipilih karena performanya yang lebih baik (dibanding Opti Flour O atau Insta Gel Plus), efisiensi hasil analisis yang lebih tinggi, dan limit deteksi yang lebih rendah (sehingga memiliki jangkauan yang lebih luas) [12]. Data hasil counting masingmasing sampel tertera pada Tabel 1, Tabel 2, dan Tabel 3. 
Tabel 1. Hasil pencacahan sampel bensin.

\begin{tabular}{|c|c|c|c|c|}
\hline \multirow{2}{*}{ Nama Sampel } & \multicolumn{2}{|c|}{ I. Rata-rata } & \multicolumn{2}{|c|}{ II. Rata-rata } \\
\hline & tSIE & cpm & tSIE & cpm \\
\hline$\overline{\mathrm{G} 0}$ & 410,816 & 14,236 & 387,464 & 13,874 \\
\hline G 2,5 & 458,382 & 14,357 & 416,298 & 15,825 \\
\hline G 5,0 & 447,947 & 16,374 & 419,495 & 18,618 \\
\hline G 7,5 & 443,017 & 19,135 & 408,235 & 20,998 \\
\hline G 10,0 & 440,287 & 21,813 & 415,005 & 23,976 \\
\hline G 15,0 & 433,164 & 25,622 & 407,019 & 28,009 \\
\hline G 20,0 & 419,730 & 29,445 & 410,234 & 31,528 \\
\hline G 30,0 & 419,163 & 34,838 & 399,938 & 38,623 \\
\hline $\mathrm{G} 40,0$ & 406,275 & 40,933 & 384,632 & 44,045 \\
\hline G 50,0 & 373,723 & 50,146 & 377,218 & 52,397 \\
\hline G 60,0 & 368,720 & 50,365 & 369,662 & 52,883 \\
\hline G 70,0 & 363,318 & 53,818 & 361,297 & 55,539 \\
\hline G 80,0 & 351,754 & 56,967 & 346,075 & 59,497 \\
\hline G 90,0 & 340,607 & 59,957 & 345,645 & 61,380 \\
\hline G 100,0 & 325,643 & 62,034 & 339,310 & 64,370 \\
\hline RBDPO I & 360,077 & 19,393 & 330,426 & 18,408 \\
\hline RBDPO II & 355,273 & 20,713 & 348,278 & 20,806 \\
\hline
\end{tabular}

Tabel 2. Data pencacahan sampel bensin dan penghitungan persentase bio-nya.

\begin{tabular}{cccc}
\hline Nama Sampel & cpm & f bio & \% \\
\hline G 0 & 14,2363 & 0 & 0 \\
G 2,5 & 14,3567 & 0,0025 & 0,2518 \\
G 5,0 & 16,3743 & 0,0447 & 4,4729 \\
G 7,5 & 19,1353 & 0,1025 & 10,2494 \\
G 10,0 & 21,8130 & 0,1585 & 15,8514 \\
G 15,0 & 25,6223 & 0,2382 & 23,8211 \\
G 20,0 & 29,4447 & 0,3182 & 31,8179 \\
G 30,0 & 34,8383 & 0,4310 & 43,1022 \\
G 40,0 & 40,9327 & 0,5585 & 55,8524 \\
G 50,0 & 50,1457 & 0,7513 & 75,1273 \\
G 60,0 & 50,3653 & 0,7559 & 75,5868 \\
G 70,0 & 53,8177 & 0,8281 & 82,8096 \\
G 80,0 & 56,9667 & 0,8939 & 89,3977 \\
G 90,0 & 59,9567 & 0,9565 & 95,6532 \\
G 100,0 & 62,0343 & 1 & 100 \\
RBDPO tahap 1 & 19,393 & 0,1079 & 10,7884 \\
RBDPO tahap 2 & 20,713 & 0,1355 & 13,5501 \\
\hline
\end{tabular}


Tabel 3. Hasil pencacahan sampel avtur.

\begin{tabular}{ccccc}
\hline \multirow{2}{*}{ Nama Sampel } & \multicolumn{2}{c}{ I. } & Rata-rata & \multicolumn{2}{c}{ II. } & Rata-rata \\
\cline { 2 - 5 } & tSIE & cpm & tSIE & cpm \\
\hline RBDPKO 2\% & 537,157 & 10,664 & 518,798 & 11,261 \\
RBDPKO 5\% & 477,412 & 12,113 & 431,112 & 12,623 \\
RBDPKO 7.5\% & 540,928 & 13,928 & 516,840 & 14,391 \\
RBDPKO 10\% & 541,440 & 14,756 & 518,624 & 15,867 \\
RBDPKO 20\% & 526,241 & 21,247 & 511,802 & 22,070 \\
RBDPKO 30\% & 531,272 & 26,078 & 513,838 & 26,666 \\
RBDPKO 40\% & 509,357 & 30,738 & 517,141 & 32,003 \\
RBDPKO 50\% & 510,117 & 35,115 & 498,725 & 36,857 \\
RBDPKO 100\% & 504,673 & 44,535 & 533,842 & 43,868 \\
\hline
\end{tabular}

Nilai tSIE berhubungan dengan kepekatan warna BBMC. Semakin pekat warna sampel maka semakin kecil nilai tSIE-nya. Berdasarkan data yang tertera pada Tabel 1, terlihat bahwa nilai cpm bensin pada pengukuran I memiliki rentang antara 14,236 dan 62,034 sementara nilai tSIE memiliki rentang antara 325,643 dan 410,816. Pengulangan counting pada sampel bensin dilakukan untuk melihat faktor linieritas dan repeatability dengan hasil yang ditunjukkan pada Tabel 1 pengukuran II. Rentang nilai tSIE dan CPM pada pengukuran II berturut-turut adalah 387,464 hingga 339,310 dan 13,874 hingga 64,370. Sampel RBDPO I dan II merupakan sampel bensin dengan konsentrasi tertentu yang berfungsi sebagai sampel uji coba. Metode yang sama, yaitu direct counting dipilih untuk melihat konsentrasi fraksi bio sampel tersebut dengan cara membandingkannya dengan deret BBMC jenis yang sama. Nilai cpm yang dihasikan kemudian dikonversi menjadi persentase bio.

Makin tinggi nilai cpm yang dihasilkan dari cacahan makin tinggi pula aktivitas C-14. Aktivitas C-14 pada BBF akan bernilai lebih rendah dibanding BBN. Hal tersebut disebabkan karena C-14 pada BBF telah meluruh dengan waktu paruh 5700 tahun [11], [17]. Data pencacahan sampel G 0-G 100 menunjukkan peningkatan nilai cpm secara linier. Peningkatan ini menunjukkan bahwa setiap penambahan komponen biogenik pada BBMC tipe bensin telah terdeteksi dengan baik.

Pada persentase 0-2,5\%, komponen biogenik tidak menunjukkan linieritas pada nilai tSIE dan nilai cpm. Namun, terdapat hubungan signifikan antara tSIE dan cpm setelah persentase 2,5\%. Hal ini terjadi baik pada pengukuran I maupun II. Pada pengukuran II terjadi penurunan nilai tSIE. Hal ini disebabkan oleh penurunan kekuatan pendar dari sintilator UGF seiring berjalannya waktu. Biasanya, kekuatan sintilasi berkurang setelah 3-6 bulan digunakan [18].

Nilai cpm bensin berbanding lurus dengan persentase bio yang didapatkan. Makin besar nilai cpm makin tinggi pula persentase bio. Jika dilihat langsung dari hasil cpm-nya (bukan berdasarkan tSIE yang diplot ke grafik), nilai cpm sampel RBDPO I dan RBDPO II adalah 19,393 dan 20,713 sementara persentase bionya adalah 10,7884 dan 13,5501. Tabel 2 menunjukkan bahwa nilai cpm dan persentase bio sampel tersebut terdeteksi berada di antara G 7,5-G 10,0.

Pada Gambar 2 terlihat bahwa koefisien korelasi $\left(\mathrm{R}^{2}\right)$ antara tSIE dan cpm lebih rendah $(0,9757)$ dibanding $\mathrm{R}^{2}$ antara pengukuran I dan 
pengukuran II $(0,9328)$. $\mathrm{R}^{2}$ yang dihasilkan pencacahan pertama lebih tinggi dari pencacahan kedua. Ketidakstabilan sintilator menyebabkan hasil pengukuran aktivitas cenderung menurun. Stabilitas sintilator akan berkurang setelah dicampur dengan sampel. Penelitian lain menunjukkan bahwa sintilator Utima Gold dan Utima Gold AB terhadap sampel ${ }^{3} \mathrm{H}$ dan ${ }^{63} \mathrm{Ni}$ juga mengalami penurunan tSIE [18].

Berdasarkan data yang disajikan pada Tabel 3, hasil tSIE dan cpm avtur tidak menunjukkan linieritas. Mudah membekunya sampel avtur dalam suhu kamar menyebabkan nilai tSIE avtur bersifat fluktuatif. Nilai cpm avtur terus meningkat secara linier seiring meningkatnya aktivitas C-14 dan persentase biogenik-nya. Terdapat beberapa fenomena quenching yang dapat memengaruhi pengukuran C-14 pada BBMC, yaitu chemical quench dan color quench. Chemical quench akan memengaruhi transmisi energi antara sintilator dan pelarut sedangkan color quench akan memengaruhi transmisi energi antara sintilator dan photomultiplier tubes (PMT) yang berakibat melemahnya pendaran sampel [19]. Faktor selain chemical quench dan color quench yang dapat berpengaruh adalah ionization quench yang menyebabkan tidak liniernya pendaran cahaya dengan energi terdeposit seiring meningkatnya massa partikel. Hal itu menyebabkan hilangnya energi eksitasi dan intensitas foton tereduksi serta penurunan cacahan [20]. Peneliti terdahulu menyebutkan bahwa efek quenching menyebabkan berkurangnya efisiensi pengukuran karena mengurangi pendaran cahaya yang dihasilkan [21].

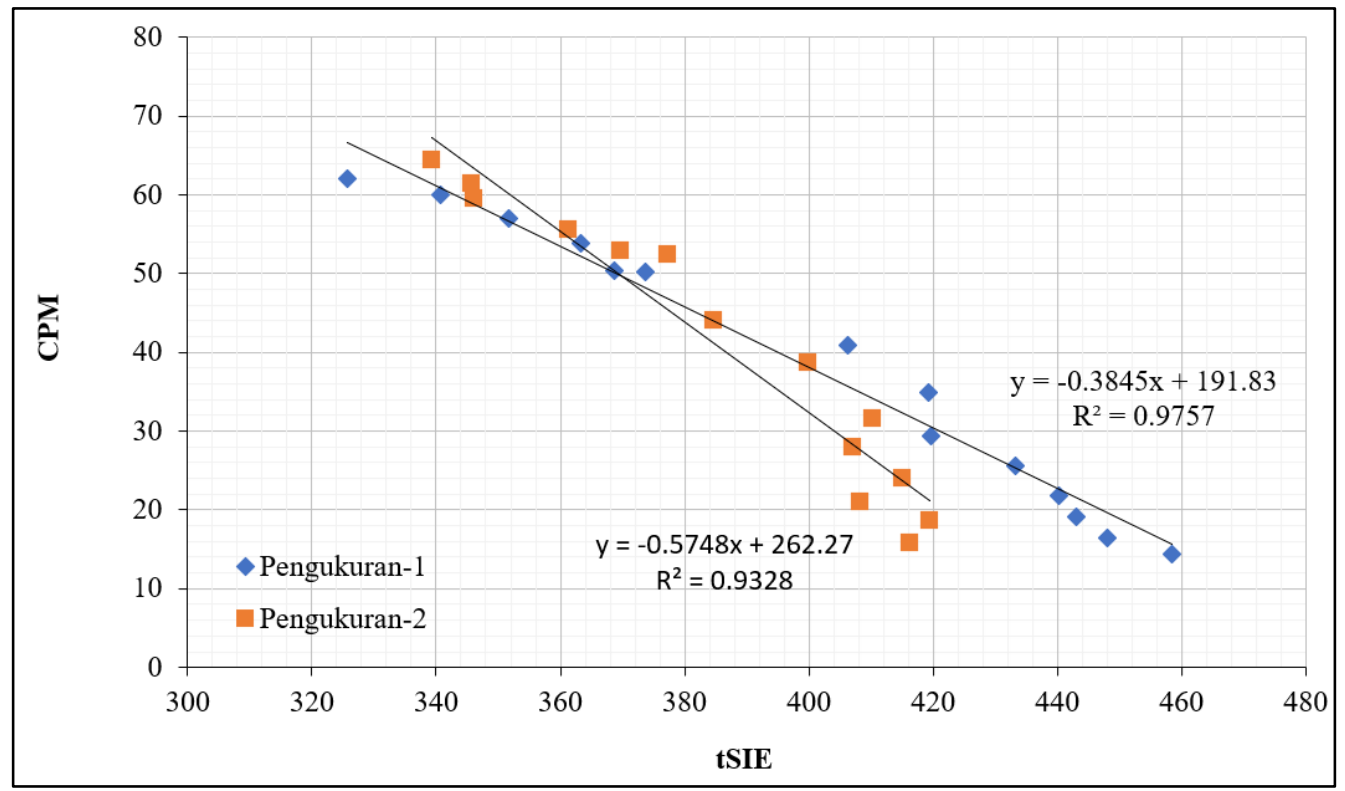

Gambar 2. Grafik korelasi tSIE dan cpm sampel bensin dalam dua pengukuran.

Grafik yang ditunjukkan pada Gambar 3 tidak memperlihatkan korelasi yang kuat antara tSIE dan cpm. Hal ini diperkuat dengan nilai regresi yang didapat untuk pengukuran I dan pengukuran II yang masing-masing adalah 0,0971 dan 0,140 .
Deret sampel avtur menunjukkan pengukuran yang baik, terindikasi dari nilai cpm sampel avtur yang mengalami kenaikan secara linier (Tabel 4). Sebagai penguji sampel A0 avtur base dan green avtur digunakan untuk melihat besaran cpm dan fraksi bio yang 
kemudian dibandingkan dengan deret standarnya. Berdasarkan uji yang telah dilakukan, nilai cpm kedua sampel tersebut secara berturut-turut adalah 9,453 dan 10,082 sedangkan fraksi bio yang dihasilkan adalah 0,036 dan -0,017. Data tersebut menunjukkan bahwa sampel A0 avtur base dan green avtur berada di luar jangkauan deret. Background yang digunakan pada deret standar sampel avtur merupakan RBDPKO 2\% sehingga cpm sampel A0 avtur base dan green avtur diperkirakan memiliki nilai $<2 \%$

Tabel 4. Data pencacahan sampel avtur dan penghitungan persentase bio-nya.

\begin{tabular}{cccc}
\hline Nama Sampel & cpm & f bio & \% \\
\hline RBDPKO 2\% & 10,664 & 0 & 0 \\
RBDPKO 5\% & 12,113 & 0,043 & 4,277 \\
RBDPKO 7,5\% & 13,928 & 0,096 & 9,636 \\
RBDPKO 10\% & 14,756 & 0,121 & 12,080 \\
RBDPKO 20\% & 21,247 & 0,312 & 31,244 \\
RBDPKO 30\% & 26,078 & 0,455 & 45,509 \\
RBDPKO 40\% & 30,738 & 0,593 & 59,266 \\
RBDPKO 50\% & 35,115 & 0,722 & 72,189 \\
RBDPKO 100\% & 44,535 & 1 & 100 \\
A0 AVTUR BASE & 9,453 & $-0,036$ & $-3,576$ \\
SAMPEL GREEN AVTUR & 10,082 & $-0,017$ & $-1,718$ \\
\hline
\end{tabular}

Data pencacahan menunjukkan peningkatan nilai cpm secara linier yang ditunjukkan pada Tabel 5 dan Gambar 4. BBM 0-100\% biodiesel ini menunjukkan bahwa setiap penambahan biodiesel pada BBM fosil sudah terdeteksi dengan baik. Nilai tSIE pada diesel ini sudah terukur dengan baik. Penambahan biodiesel berbanding lurus secara linier terhadap nilai tSIE dan cpm sehingga terdapat korelasi yang kuat antara tSIE vs. cpm. Untuk sampel BBM dari co-processing (minyak diesel RBDPO), nilai tSIE hasil analisis berada di luar range sehingga persentase biodiesel dalam BBM tidak dapat ditentukan berdasarkan deret standarnya. Hal ini mungkin disebabkan karena $\mathrm{CO} 2$ dalam BBM sudah terlepas ketika dilakukan pemanasan di kilang bahan bakar minyak.

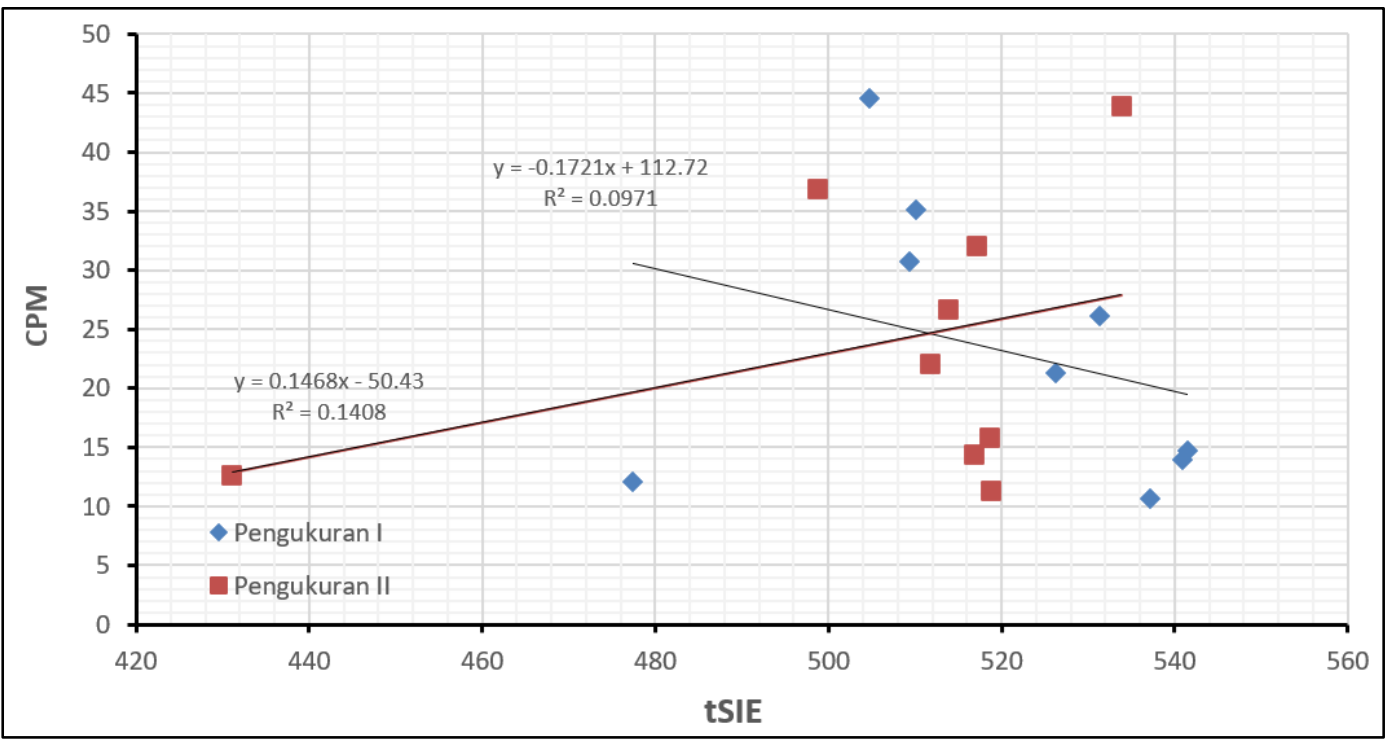

Gambar 3. Grafik korelasi tSIE dan cpm sampel avtur dalam dua pengukuran. 
Tabel 6 memperlihatkan kenaikan persentase seiring meningkatnya komponen biogenik yang ditambahkan. Jika hasil analisis sampel solar RBDPO dilihat hanya berdasarkan nilai cpm maka sampel terdeteksi berada di antara D 5,0-D 7,5. Interpretasi tersebut dapat memberikan gambaran bahwa sampel minyak diesel RBDPO memiliki konsentrasi $\mathrm{BBF} 6,9 \%>\mathrm{X}>4,8 \%$. Untuk menentukan nilai $\mathrm{X}$ secara akurat dilakukan penghitungan fraksi bio terhadap sampel tersebut. Sampel solar RBDPO menunjukkan nilai $6,6930 \%$ sesuai dengan pendekatan nilai cpm yang berada di kisaran D 5,0-D 7,5. Hasil ini menunjukkan korelasi yang sama dengan penelitian terdahulu [6] dalam penentuan persentase fraksi BBN pada BBMC. Penelitian tersebut berhasil menentukan deret persentase fraksi BBN dari 0-100\% berdasarkan perbandingan pencampuran berbagai jenis bahan bakar. Makin besar fraksi bio yang ditambahkan makin meningkat pula persentase fraksi BBN [11].

Pada penelitian lain, diperoleh korelasi yang baik antara metode LSC dan Accelerator Mass Spectrometry (AMS) berdasarkan analisis statistik [22]. Koreksi quenching dilakukan untuk meningkatkan akurasi pengukuran, terutama untuk sampel berwarna gelap [23]. Teknik direct counting ini dapat digunakan sebagai referensi pembanding dan metode praktis untuk penentuan konsentrasi bio pada BBMC untuk keperluan regulasi fungsi kontrol pasar BBMC atau evaluasi dalam strategi pemanfaatan $\mathrm{BBN}$ di suatu negara [6].

Tabel 5. Hasil pencacahan sampel solar.

\begin{tabular}{ccc}
\hline \multirow{2}{*}{ Nama Sampel } & \multicolumn{2}{c}{ Rata-rata } \\
\cline { 2 - 3 } D 0 & 152,051 & CPM \\
\hline D 2,5 & 151,845 & 10,475 \\
D 5,0 & 157,118 & 11,473 \\
D 7,5 & 159,784 & 12,394 \\
D 10,0 & 158,167 & 13,684 \\
D 12,5 & 161,363 & 14,818 \\
D 15,0 & 158,113 & 15,621 \\
D 20,0 & 160,755 & 18,018 \\
D 30,0 & 171,840 & 22,897 \\
D 40,0 & 180,642 & 26,530 \\
D 50,0 & 186,118 & 31,493 \\
D 60,0 & 196,733 & 36,744 \\
D 70,0 & 205,375 & 42,153 \\
D 80,0 & 213,877 & 46,479 \\
D 90,0 & 229,956 & 54,526 \\
D 100,0 & 243,776 & 61,789 \\
Minyak diesel RBDPO & 119,158 & 12,286 \\
\hline & &
\end{tabular}


Tabel 6. Data pencacahan sampel solar dan penghitungan persentase bio-nya.

\begin{tabular}{cccc}
\hline Nama Sampel & cpm & f bio & \% \\
\hline D 0 & 9,4097 & 0 & 0 \\
D 2,5 & 10,4747 & 0,0248 & 2,4784 \\
D 5,0 & 11,4727 & 0,0480 & 4,8010 \\
D 7,5 & 12,3943 & 0,0694 & 6,9459 \\
D 10,0 & 13,6840 & 0,0994 & 9,9472 \\
D 12,5 & 14,8177 & 0,1258 & 12,5855 \\
D 15,0 & 15,6213 & 0,1445 & 14,4558 \\
D 20,0 & 18,0180 & 0,2003 & 20,0333 \\
D 30,0 & 22,8970 & 0,3138 & 31,3877 \\
D 40,0 & 26,5297 & 0,3984 & 39,8417 \\
D 50,0 & 31,4930 & 0,5139 & 51,3924 \\
D 60,0 & 36,7440 & 0,6361 & 63,6125 \\
D 70,0 & 42,1533 & 0,7620 & 76,2012 \\
D 80,0 & 46,4793 & 0,8626 & 86,2687 \\
D 90,0 & 54,5257 & 1,0499 & 104,9941 \\
D 100,0 & 61,7893 & 1,2189 & 121,8982 \\
Minyak diesel RBDPO & 12,2857 & 0,0669 & 6,6930 \\
\hline
\end{tabular}

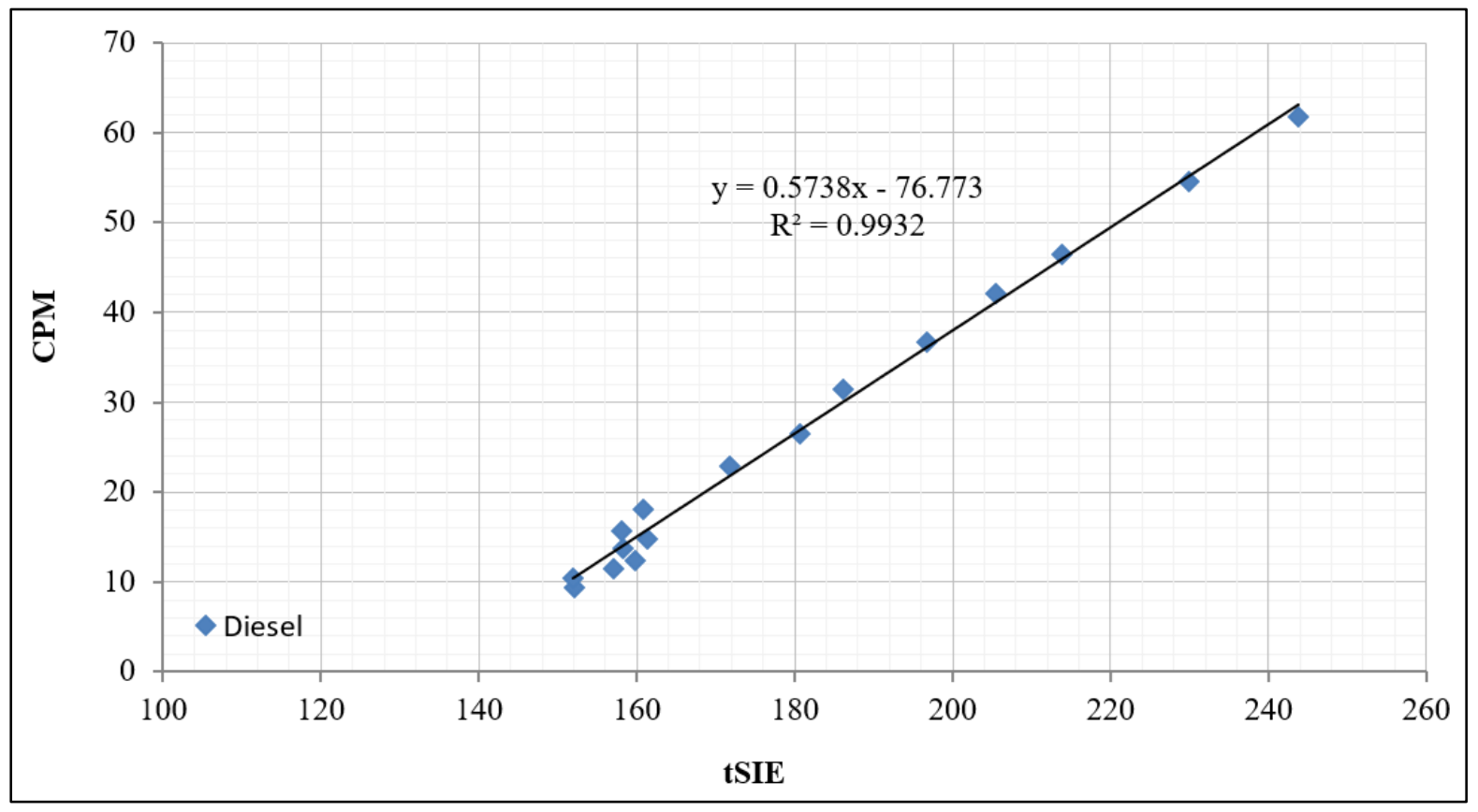

Gambar 4. Grafik korelasi tSIE dan cpm sampel solar.

\section{KESIMPULAN}

Secara umum, aktivitas ${ }^{14} \mathrm{C}$ dalam BBM sudah terdeteksi dengan baik oleh alat Liquid Scintillation Counter (LSC) yang ditunjukkan dengan peningkatan nilai count per minute (cpm) pada setiap penambahan persentase biogasoline, bioavtur, dan biodiesel. Terdapat korelasi yang kuat antara tSIE vs. CPM, kecuali pada bioavtur. Namun demikian, metode ini masih belum memberikan kepastian hasil ketika diterapkan untuk penentuan persentase sampel co-processing. 
Jika hasil analisis hanya didasarkan pada nilai cpm (tanpa melihat nilai tSIE-nya) maka persentase RBDPO gasoline, baik dari pengukuran I maupun pengukuran II terdeteksi berada di antara G 7,5-G 10,0. Sementara itu, persentase RBDPO biodiesel terdeteksi berada di antara D 5,0-D 7,5.

\section{Saran}

Pengukuran komponen biogenik dalam sampel yang berasal dari co-processing menggunakan metode direct counting LSC belum memberikan hasil yang baik. Untuk itu, diperlukan metode lain, yaitu metode sintesis benzena atau metode Carbosorb. Agar dapat menggunakan salah satu dari kedua metode tersebut, diperlukan alat tambahan yang dapat mengonversi BBMC menjadi ${ }^{14} \mathrm{CO}_{2}$. Dua hal yang dapat dilakukan adalah sebagai berikut:

1. mengubah BBMC (cair) menjadi padatan anorganik dalam bentuk senyawa $\mathrm{CaCO}_{3}$ dan

2. membakar BBM menggunakan alat Parr-Combustion sehingga terbentuk ${ }^{14} \mathrm{CO}_{2}$.

Apabila salah satu dari kedua proses di atas berhasil dilakukan maka pada proses selanjutnya dapat digunakan metode sintesis benzena (ASTM 6866-08) atau metode Carbosorb untuk menentukan persentase BBN pada BBMC dalam satuan percent modern carbon (PMC).

\section{UCAPAN TERIMA KASIH}

Terima kasih kami ucapkan kepada rekan sejawat kami bapak Drs. Satrio, rekan-rekan di Laboratorium Hidrologi dan Panas bumi PAIR, serta Puslitbangtek Migas-Kementerian ESDM yang telah membantu sehingga makalah ini dapat diselesaikan.

\section{DAFTAR PUSTAKA}

[1] Kementerian Energi dan Sumber Daya Mineral, Rencana Strategis Kementerian Energi dan Sumber Daya Mineral 2015-2019. 2015.

[2] BPS, BP Statistical Review 2015: Pasar Energi Indonesia 2014. Badan Pusat Statistik, 2015.

[3] Kementerian PPN/Bappenas, Kajian Pengembangan Bahan Bakar Nabati (BBN). Direktorat Sumber Daya Energi, Mineral, dan Pertambangan, Kementrian PPN/Bappenas, 2015.

[4] Rahmawati, "Pengujian Mutu Biofuel Berbasis 14C dan Kandungan Unsur-Unsur Runut (Trace Elements)," Universitas Hasanuddin, 2018.

[5] M. D. Sholikhah, "Pengembangan Metoda Kontrol Kualitas untuk Uji Mutu Biodiesel yang dapat Diterapkan Oleh Industri Kecil-Menengah," Jakarta, 2010.

[6] R. Kristof, M. Hirsch, and J. K. Logard, "Implementation of Direct LSC Method for Diesel Samples on The Fuel Market," Appl. Radiat. Isot., vol. 93, no. April, pp. 101-105, 2014, doi: 10.1016/j.apradiso.2014.04.003.

[7] I. J. Dijs, E. van der Windt, L. Kaihola, and K. van der Borg, "Quantitative Determination by 14C Analysis of The Biological Component in Fuels," Radiocarbon, vol. 48, no. 3, pp. 315-323, 2006, doi: $10.1017 / \mathrm{S} 0033822200038777$.

[8] J. Noakes, G. Norton, R. Culp, M. Nigam, and D. Dvoracek, "A Comparison of Analytical Methods for The Certification of Biobased Products," in LSC 2005, Advances in Liquid Scintillation Spectrometry, 2006, pp. 259-271.

[9] S. Yunoki and M. Saito, "A Simple Method to Determine Bioethanol Contentin Gasoline Using Two-Step Extraction and Liquid Scintillation Counting," Bioresour. Technol., vol. 100, no. 23, pp. 6125-8, 2009, doi: 10.1016/j.biortech.2009.06.027.

[10] Y. Takahashi, H. Sakurai, E. Inui, S. Namai, and S. Sato, "Radiocarbon Measurement of Biodiesel Fuel Using The Liquid Scintillation Counter Quantulus. In: Cassette, P.(Ed.), LSC 2010, Advances in Liquid Scintillation Spectrometry.," in LSC 2010, Advances in Liquid Scintillation Spectrometry, 2011, pp. 41-44.

[11] R. Krištof and J. K. Logar, "Direct LSC Method for Measurements of Biofuels in Fuel," Talanta, vol. 111, pp. 183-188, 2013, doi: 10.1016/j.talanta.2013.03.009.

[12] R. Idoeta, E. Pérez, M. Herranz, and F. Legarda, "Characteristic Parameters in the Measurement of 14C of Biobased Diesel Fuels by Liquid Scintillation," Appl. Radiat. Isot., vol. 93, pp. 110113, 2014, doi: 10.1016/j.apradiso.2014.01.019.

[13] R. Edler and L. Kaihola, "Determination of the 14C Content in Fuels Containing Bioethanol and Other Biogenic Materials with Liquid Scintillation Counting," 2007. 
[14] W. G. Mook and J. van der Plicht, "Reporting 14C Activities and Concentrations," Radiocarbon, vol. 41, no. 3, pp. 227-239, 1999, doi: $10.1017 / \mathrm{s} 0033822200057106$.

[15] M. Stomp-Smit, J. ter Wiel, and R. Edler, "Determination of the 14C Content in Biodiesel. A Method Improving the Detection Sensitivity by Decolorizing the Biogenic Material in Biofuel," 2010.

[16] I. K. Bronić, J. Barešić, N. Horvatinčić, and A. Sironić, "Determination of Biogenic Component in Liquid Fuels by the 14 C Direct LSC Method by Using Quenching Properties of Modern Liquids for Calibration," Radiat. Phys. Chem., vol. 137, pp. 248-253, 2017, doi: 10.1016/j.radphyschem.2016.01.041.

[17] R. Edler and L. Kaihola, "Differentiation between Fossil and Biofuels by Liquid Scintillation Beta Spectrometry-Direct Method," Nukleonika, vol. 55, no. 1, pp. 127-131, 2010.

[18] Y. Nedjadi, P.-F. Duc, F. Bochud, and C. J. Bailat, "On the Stability of $3 \mathrm{H}$ and $63 \mathrm{Ni}$ Ultima Gold Liquid Scintillation Sources," Appl. Radiat. Isot., vol. 118, pp. 25-31, 2016, doi: 10.1016/j.apradiso.2016.08.017.

[19] R. Krištof and J. K. Logar, "Liquid Scintillation Spectrometry as a Tool of Biofuel Quantification," in Frontiers in Bioenergy and Biofuels, E. JacobLopes, Ed. IntechOpen, 2017, pp. 59-69.

[20] M. F. L’Annunziata, A. Tarancón, H. Bagán, and J. F. García, "Liquid Scintillation Analysis: Principles and Practice," in Handbook of Radioactivity Analysis, 4th ed., vol. 1, M. F. L'Annunziata, Ed. Academic Press, 2020, pp. 575-801.

[21] C. G. Doll, C. W. Wright, S. M. Morley, and B. W. Wright, "Analysis of Fuel Using the Direct LSC Method Determination of Bio-Originated Fuel in the Presence of Quenching," Appl. Radiat. Isot., vol. 122, no. November 2016, pp. 215-221, 2017, doi: 10.1016/j.apradiso.2017.01.040.

[22] M. Hurt, J. Martinez, A. Pradhan, M. Young, and M. E. Moir, "Liquid Scintillation Counting Method for the Refinery Laboratory-Based Measurements of Fuels to Support Refinery BioFeed Co-Processing," Energy and Fuels, vol. 35, no. 2, pp. 1503-1510, 2021, doi: 10.1021/acs.energyfuels.0c03445.

[23] C. G. Doll et al., "Determination of Low-Level Biogenic Gasoline, Jet Fuel, and Diesel in Blends Using the Direct Liquid Scintillation Counting Method for 14C Content," Fuel, vol. 291, 2021, doi: 10.1016/j.fuel.2020.120084. 
Penentuan Komposisi Bahan Bakar Nabati Dalam Bahan Bakar Minyak Campuran Menggunakan Metode Direct Counting C-14 Oleh: Neneng Laksminingpuri, $d k k$. 